\title{
CREATION OF A STRUCTURAL MODEL OF AN POWER TRANSFORMERS IN THE FORM OF AC TRANSFORMING COMPLEXES
}

\section{Dmytro Yarymbash ${ }^{1}$ \\ Mykhailo Kotsur ${ }^{2}$}

DOI: https://doi.org/10.30525/978-9934-26-001-8-2-13

Abstract. Due to the multiple transformation of electrical energy, the rated ca-pacity of power transformers can be 8 or more times the rated generation capacity. Therefore, the state of reliability of power transformers, their parameters and characteristics affecting on the reliability and efficiency of power networks, electrical pro-duction facilities, and electrical equipment of consumers. High indicators of operational reliability should be provided by the corresponding level of quality of design of power transformers both at a stage of development of tender offers, and during preparation of production of new or modernized types of power transformers. Im-proving approaches to design and increasing the accuracy of design data requires the use of modern specialized software for spatial modeling of electromagnetic and electro-thermal processes in testing and rated modes of operation based on 3D geometric models of parts, assemblies, systems in the active parts of power transformers. To improve the design quality of power transformers, a unitary structure is proposed, which combines tuples of design data of certain types of power transformers. Creation of a unitary structure of power transformer projects for the production program of the enterprise provides a significant time reduction to develop projects of new types of power transformers by importing the generated design data of the same parts, components, systems from previously developed power transformer projects. Application of unitary structure of power transformers projects allows to reduce time for

\footnotetext{
${ }^{1}$ Doctor of Technical Sciences, Professor, Head of Electrical Machine Department,

Zaporizhzhia Polytechnic National University, Ukraine

${ }^{2}$ Candidate of Technical Sciences, Associate Professor, Electrical and Electronic Apparatuses Department, Zaporizhzhia Polytechnic National University, Ukraine

(C) Dmytro Yarymbash, Mykhailo Kotsur
} 
creation and import of detailed 3D geometric model of power transformer in structure of specialized software of field modeling of electromagnetic and electro-thermal processes. This allows to significantly reduce the cost of design preparation of production, increase the accuracy of design data and implement design solutions to increase the level of reliability and efficiency of operation of power transformers. Therefore, the design data for the unavailable parts, components, elements of individual systems in a transformer are displayed in the corresponding design tuple "zero" elements. For development of projects of new types of power transformers, import of the structured design data of identical details, knots, systems of earlier developed projects of power transformers is carried out. Updating the unitary structure of power transformers is provided by supplementing the existing unitary structure with a tuple of design data of a new type of power transformer. This provides a significant reduction in design time and increase the accuracy of determining new design data.

\section{Introduction}

At the present stage of development of productive forces, considerable atten-tion is paid to energy security, as well as the security of energy supply systems [1, p. 50]. It is known, that the economic losses of consumers from accidents in power systems and energy equipment can be in several orders exceed the economic losses in energy suppling companies [2, p. 143]. There is a tendency to more widespread usage in modern power systems of ultrahigh voltage classes and ultra-high unit power [3, p. 22]. This allows to reduce power losses in power systems and provide much better specific factors of active materials (ferromagnetic, conductive) per unit of rated capacity of electrical equipment [4, p. 151].

Transportation and distribution of electricity between consumers requires multiple conversions from one voltage value to another under a constant value of the AC frequency. A multiplicity of such transformations of AC electric energy is usually equal to 8 and more [5, p. 22]. Therefore, the rated capacity of power transformers must be 8 times or more than the capacity of power generation sources $[6, p .55]$. The reliability of power transformers in operation mode, the time constancy of their parameters and characteristics determine the energy efficiency of power systems, electrical networks and electrical equipment [7, p. 5]. 
Reliability and technical factors are determined by the quality level of design of power transformers, development of new innovative technical solutions based on 3D modeling of electromagnetic processes in different operating and emergency modes [8, p. 122]. It is $3 \mathrm{D}$ modeling that requires accurate display of the geometry of systems, components, parts of electrical equipment and their mutual positions. In addition, there is a need for a mathematical description of the physical properties and characteristics of active, insulating materials with high accuracy $[9$, p. 121].

A Transformer constructing enterprises has a nomenclature of transformer's equipment of different types, capacities and voltage classes. A Power transformers of different types has a significant difference in the design of magnetic systems, winding systems, electrical insulation systems, cooling systems, voltage regulation and etc. This validate requirement for mathematical abstract of the design structure of power transformers, a design structure of their systems, geometric features of their parts and components and physical properties of their materials, based on the creation of a unitary structural model of power transformers.

\section{General structural model of power transformer}

The structural model of a power transformer is created by interconnected systems: magnetic system, winding system, connection terminal systems for different voltage sides, external and internal electrical insulation systems, voltage regulation systems (VRS) and switching devices without field (SDWF), systems protection and control and measuring devices. Rated data and characteristics of a power transformer, its technical and economic indicators are determined by the features of the complex constructive structure, as a finite set of interconnected operating elements. The active part of the power transformer can be defined as the final element of the specified structure, because in its geometrical area the $\mathrm{AC}$ electric energy conversation with one parameters to others at constant frequency is carried out.

An electrical energy conversion process is carried out in a power transformer, as in a static device. That is, without any changes in the shape of its structural elements or their position relative to each other. For the components of a power transformer, these processes are not dynamic or shape-changing. Therefore, for the final objective, we can take the set of rated electrical $E_{A}=\left\{e_{A, \alpha}\right\}$, energy $H_{A}=\left\{h_{A, \alpha}\right\}$, temperature parameters 
$T_{A}=\left\{t_{A, \alpha}\right\}$ and characteristics $M_{A}=\left\{m_{A, \alpha}\right\}$ which are determined for each type of an transformer equipment with taking into account the allowable allowances according to international standards and a explicit level of reliability in emergency states (sudden short circuits, overloads, over voltages, etc.):

$$
\begin{gathered}
A=\left\{E_{A}, H_{A}, T_{A}, M_{A}\right\}=\left\{c_{A, \alpha}\right\}=\left\{\left\{e_{A, \alpha}\right\},\left\{h_{A, \alpha}\right\},\left\{\mathrm{t}_{A, \alpha}\right\},\left\{m_{A, \alpha}\right\}\right\}, \\
\alpha=\overline{1, \chi_{A}},
\end{gathered}
$$

where $\alpha$-number of types of transformer production; $\chi_{A}-$ the total number of titles of the corresponding types and varieties in the classification of production.

The set of types and varieties of an power transformers in accordance with the production program of the enterprise should be considered as a set of production objects $\{\alpha\}$. The technological complex of the transformer's enterprises should provide production of any type of a power transformers, according to the production program. Also the technological capacity of the enterprise must have a potential redundancy, relative to the set of objectives, according to (1) - (2), to ensure the release of new types of products.

\section{Structural model of the active part of power transformer 3.1 Structural model of a magnetic system}

To describe the active part, as the final element of the structure of the $i$-th power transformer with a given voltage class and a group of dimensions, it is necessary to create a set of its systems and subsystems, including a set of magnetic systems. A magnetic system of the transformer is designed to localize and reduce a magnetic resistance of magnetic fluxes, which generated by the windings of different phases and sides of the transformer. Cold-rolled electrical steels are used for the manufacture of magnetic systems. A Magnetic system has a different shape: spatial, planar, rods, armor-rod and armor. They are burdened from separate plates or wound with tapes from electro-technical steel. Therefore, mathematical descriptions of the structures of a magnetic systems of power transformers will be determined by:

$$
q_{i, \alpha}^{\mathrm{ms}}=\left\{\varphi_{i, \alpha}^{\mathrm{ms}}, g_{i, \alpha}^{\mathrm{ms}}, \sigma_{i, \alpha}^{\mathrm{ms}}, \mu_{i, \alpha}^{\mathrm{ms}}, h_{i, \alpha}^{\mathrm{ms}}, \xi_{i, \alpha}^{\mathrm{ms}}, f_{i, \alpha}^{\mathrm{ms}}\right\},
$$


where $i \in N^{\mathrm{ms}}, \alpha \in\left(1, \chi_{A}\right) ; \varphi_{i, \alpha}^{\mathrm{ms}}=\left\{\Phi_{i, j}^{\mathrm{ms}}\right\}_{\alpha}$ is a subset of permissible types of magnetic system, which includes a typical shape (3D spatial or $2 \mathrm{D}$ flat), the number of phases, legs, the presence of side yokes, the number of frames of the magnetic system, methods of their interleaving, shapes of angles and types of joints; methods of their pressing of a legs and yoke and their bridle, types and materials of yoke pressing beams, number and types of cooling channels, etc.); $g_{i, \alpha}^{\mathrm{ms}}=\left\{G_{i, j}^{\mathrm{ms}}\right\}_{\alpha}$ is a subset of the geometric dimensions of the magnetic system, which includes arrays of geometric dimensions and coordinates: a legs packages; upper, lower and lateral yokes; cooling channels; interaxal dimensions and dimensions of a magnetic system windows; joint angles; batch schemes; location of glass bandages, semi-bandages; geometric dimensions and coordinates of the location of a yoke beams, their fastening, tightening plates or pins, etc. (the index " $m c$ " indicates - belongs to a subset of the magnetic system or a subset of its geometric dimensions and coordinates. Their total dimension is $\mathrm{N}_{\varphi}^{\mathrm{ms}}$ or $\mathrm{N}_{g}^{\mathrm{ms}}$ (index $i$-corresponds to the number from the nomenclature of production of transformers of a given type; index $j$ - corresponds to the elements, which consist the frame and the magnetic system of the power transformer; $\left\{\mu_{i, \alpha}^{\mathrm{ms}}\right\},\left\{\sigma_{i, \alpha}^{\mathrm{ms}}\right\}$ are subsets of magnetic and electrical parameters of conductive and ferromagnetic materials of constituent units, parts, components of the magnetic system and the core of the active part of the power transformer (function's arrays for magnetic permeability of materials, arrays of temperature dependences for effective electrical conductivity of materials with corresponding temperatures. The matrix formation of such dependences is applied in the absence of the corresponding functional descriptions); $h_{i, \alpha}^{\mathrm{ms}}=\left\{H_{i, \alpha}^{\mathrm{ms}}\right\}$ are subsets of thermo-physical parameters for a magnetic system, which include arrays of values of effective specific heat capacity, effective coefficients of thermal conductivity of materials, effective heat transfer coefficients for the corresponding heat transfer mechanisms and their associated temperature's arrays (tabular initiation of these dependencies is used in the absence of appropriate functional descriptions); $\left\{\xi_{i, \alpha}^{\mathrm{ms}}\right\}$ are subsets of compression and contraction forces of legs and yokes $\left\{\xi_{i, \alpha}^{\mathrm{ms}}\right\} ; f_{i, \alpha}^{\mathrm{ap}}=\left\{F_{i, \alpha}^{\mathrm{ap}}\right\}$ are subsets of functional connections $f_{i, \alpha}^{\mathrm{ap}}=\left\{F_{i, \alpha}^{\mathrm{ap}}\right\}$ for the specified type of magnetic system ${ }^{\alpha}$-th transformer. 


\subsection{Structural model of the winding system}

A system of windings of a power transformer also refers to the main systems, that provide the conversion of electrical energy from some $\mathrm{AC}$ current and voltage values to others. According to setting of the transformer's winding, it is divided into inducing winding, teaser winding, and compensating winding, etc. Depending on the operating voltages and currents, it can be of different types: cylindrical-shaped, multilayer-shaped, coil-shaped, intertwinedshaped, screw-shaped, single and multi-pass-shaped, spiral-shaped. For transformer's winding is used a wires of round and rectangular shapes, which can contain several parallel wires with their cross connection with a certain step along the length. The windings of different phases, different setting (inducing winding, teaser winding, and compensating winding, etc.) are connected by lead-out system for the corresponding sides of the transformers according to certain circuit. A winding system thereby created is the main system of the active part of the transformer.

So, for the active part, the set of transformer winding systems is determined by:

$$
q_{i, \alpha}^{\mathrm{ws}}=\left\{\varphi_{i, \alpha}^{\mathrm{ws}}, g_{i, \alpha}^{\mathrm{ws}}, \mathrm{w}_{i, \alpha}^{\mathrm{ws}}, \sigma_{i, \alpha}^{\mathrm{ws}}, h_{i, \alpha}^{\mathrm{ws}}, \xi_{i, \alpha}^{\mathrm{ws}}, f_{i, \alpha}^{\mathrm{ws}}\right\},
$$

where $i \in N^{\mathrm{ws}}, \alpha \in\left(1, \chi_{A}\right) ; \varphi_{i, \alpha}^{\mathrm{ws}}=\left\{\Phi_{i, j}^{\mathrm{ws}}\right\}_{\alpha}$ is a subset of permissible types of dimension type of winding system, which includes screw, coil, spiral, layered (multilayer), multi-pass, block and other types of windings; $\varphi_{i, \alpha}^{\mathrm{ws}}=\left\{\Phi_{i, j}^{\mathrm{ws}}\right\}_{\alpha}$ is a subset of the geometric dimensions of a windings system, which includes arrays of geometric dimensions and coordinates of coils, concentrates, layers, winding wires, paper insulation, fields between axial rods, horizontal and vertical channels, barriers, laying, angle washers, etc.; $\mathrm{w}_{i, \alpha}^{\mathrm{ws}}=\left\{W_{i, j}^{\mathrm{ws}}\right\}_{\alpha}$ is a subset of winding data for a windings system with the distribution of turns on the windings, layers of coils, control-coil travel, control stages, etc. (index "ws" is denoted belonging to a subset of the winding system or a subset of their geometric dimensions and coordinates. The total dimension of which is $\mathrm{N}_{\alpha}^{\mathrm{ws}}$; index $i$ is corresponds to the number from the nomenclature of production of transformers of a given type; index $j$ is corresponds to the elements of the transformer windings); $\left\{\sigma_{i, \alpha}^{\mathrm{ws}}\right\}$ is a subset of electrical parameters of conductive materials for components, parts, components of the winding system of the active part of the power 
transformer, which include arrays of temperature dependences for the effective electrical conductivity of materials with their real temperatures (matrix formation of such dependences is applied in the absence of the corresponding functional descriptions); $\left\{\xi_{i, \alpha}^{w_{i}}\right\}$ is a subset of tonnage of the initial pressing of the windings; $h_{i, \alpha}^{\mathrm{ws}}=\left\{H_{i, \alpha}^{\mathrm{ws}}\right\}$ - are subsets of thermophysical parameters of the winding system. These include arrays of values of effective specific heat, effective thermal conductivity of materials, effective heat transfer coefficients for convective heat transfer mechanism and corresponding arrays of temperatures (tabular initiation of these dependencies is used in the absence of appropriate functional descriptions); $f_{i, \alpha}^{\mathrm{ws}}=\left\{F_{i, \alpha}^{\mathrm{ws}}\right\}$ are subsets of perfect relationship of the $\alpha$-th transformer, witch correspond to the active part of the winding types.

\subsection{Structural model of lead-out system}

The active part is connected to the system of external lead-in by leadout system, and is the final element of the power transformer. This lead-out system contains the lead-out subsystems of low-voltage winding, mediumvoltage winding (if available) and high-voltage winding, with area of a leadout subsystems to VRS and SDWF. Therefore, the structure of the active part of a transformer must be supplemented by a finite set of interacting and interconnected connecting elements.

For the $\eta$-th active element of the lead-out system (to ensure the operation of the $i$-th active part), a set is formed:

$$
q_{i, \eta, \alpha}^{\text {los }}=\left\{g_{i, \eta}^{\text {los }}, e_{i, \eta}^{\text {los }}, h_{i, \eta}^{\text {los }}, \theta_{i, \eta}^{\text {los }}, z_{i, \eta}^{\text {los }} f_{i, \eta, \alpha}^{\text {los }}\right\}
$$

where $i \in\left(1, N^{\text {los }}\right), \eta \in\left\{\mathrm{H}_{i}\right\} ; \mathrm{H}_{i}$ is a number of wires, details and assemblies, electrical insulating and cooling medias for the active element of the lead-out system; $g_{i, \eta}^{\text {los }}=\left\{G_{i, l, \eta}^{\text {los }}\right\}$ is a subset of design parameters (dimensions, coordinates of the geometric model); $e_{i, \eta}^{\text {los }}=\left\{E_{i, l, \eta}^{\text {los }}\right\}$ are subsets of magnetic and electrical parameters; $h_{i, \eta}^{\text {los }}=\left\{H_{i, l, \eta}^{\text {los }}\right\}$ are subsets of thermophysical parameters; $\theta_{i, \eta}^{\text {los }}=\left\{\Theta_{i, l, s, \eta}^{\text {los }}\right\}$ are subsets of temperature modes of operation; $z_{i, \eta}^{\text {los }}=\left\{R_{i, l, \eta}^{\text {los }}, X_{i, l, \eta}^{\text {los }}, Z_{i, l, \eta}^{\text {los }}\right\}$ are subsets of active, reactive resistances and impedances; $f_{i, \eta, \alpha}^{\text {los }}=\left\{F_{i, \eta, \alpha}^{\text {los }}\left(g_{i, \eta}^{\text {los }}, e_{i, \eta}^{\text {los }}, h_{i, \eta}^{\text {los }}, \theta_{i, \eta}^{\text {los }}, z_{i, \eta}^{\text {los }}\right)\right\}$ are subsets of functional relations. 
Based on the (5) the structure of the lead-out system of the $i$-th active part is formed, which is a part of power transformers $\forall \alpha \in\left\{M_{i}\right\}$ :

$$
q_{i, \alpha}^{\text {los }}=\left\{q_{i, \eta, \alpha}^{\operatorname{los}}\right\},
$$

where $i \in N^{\text {los }}, \eta \in\left\{\mathrm{H}_{i}\right\}$.

\section{Synthesis of a structural model of a power transformer}

Thus, the final elements of a definited dimension type of a power transformers, which are predetermined the structures of the active parts, including: the structure of magnetic systems, winding systems and lead-out system:

$$
q_{i, \alpha}^{\mathrm{ap}}=\left\{q_{i, \alpha}^{\mathrm{ms}}, q_{i, \alpha}^{\mathrm{ws}}, q_{i, \alpha}^{\mathrm{los}}\right\},
$$

where $i \in N^{\text {ap }} ; \alpha \in\left(1, \chi_{A}\right)$.

Therefore, the final elements can provide the conversion of electrical energy with different operating voltages, power, voltage classes, circuits and connection groups of windings of different phases, ranges and degrees of voltage regulation for different voltage sides for the production range. That is, the achievement of one or a group of task from the set (1), (2), which corresponds to the local substructure of the final elements - the active parts:

$$
q_{i}^{\text {ap }}=\left\{q_{i, \alpha}^{\text {ap }}\right\},
$$

where $i \in N^{\text {ap }} ; \forall \alpha \in\left\{M_{i}\right\} ;\left\{M_{i}\right\} \in\left(1, \chi_{A}\right)$.

Therefore, the set of final elements of the macrostructure of a type of transformer includes all local substructures (7), (8). It can correspond to the nomenclature set of transformer products:

$$
Q^{\mathrm{ap}}=\left\{q_{i}^{\mathrm{ap}}\right\},
$$

where $\forall i \in\left(1, N^{\mathrm{tr}}\right)$.

For each active part of the transformer from the set of final elements (9) it is possible to create a finite set of specializations, which is defined as a Cartesian product [10, p. 217] of sets of parameters and characteristics for the corresponding design of a corresponding type of power transformer (5) and independent conditions in electrical networks:

$$
S_{i}^{\mathrm{ap}}=\left\{s_{i, \alpha}^{\mathrm{ap}}\right\},
$$

where $\alpha \in\left\{M_{i}\right\} ; M_{i} \in\left(1, \chi_{A}\right) ; \forall i \in\left(1, N^{\mathrm{tr}}\right)$. 
In addition, the calculation methods of the stage of design preparation for production for explicit sets of power transformers, additionally creating a subset of the calculated nominal parameters with functional relationships between them:

$$
q_{i, j}^{\mathrm{tr}}=\left\{\zeta_{i, j}^{\mathrm{im}}, \zeta_{i, j}^{\mathrm{scm}}, \mathrm{\kappa}_{i, j}^{\mathrm{scm}}, \mathrm{i}_{i, j}^{\mathrm{scm}}, \mathrm{u}_{i, j}^{\mathrm{tr}}, z_{i, j}^{\mathrm{tr}}, f_{i, j}^{\mathrm{tr}}\right\},
$$

where $i \in\left(1, N^{\mathrm{s}}\right), \quad j \in\left(1, N^{\mathrm{tr}}\right) ; \zeta_{i, j}^{\mathrm{im}}=\left\{\Pi_{i, j, n}^{\mathrm{im}}\right\} \quad$ is a subset of the parameters of idle mode (idle current and losses for rated voltage); $\zeta_{i, j}^{\mathrm{scm}}=\left\{\Pi_{i, j, n}^{\mathrm{scm}}\right\}$ is a subset of short-circuit parameters (voltage and short-circuit losses for rated currents in paired experimental modes); $\mathbf{K}_{i, j}^{\mathrm{scm}}=\left\{\mathrm{K}_{i, j, n}^{\mathrm{scm}}\right\}$ is a subset of transformation coefficients for rated voltage values; $i_{i, j}^{\text {scm }}=\left\{I_{i, j, n}^{\mathrm{scm}}\right\}$ is a subset of rated currents on the low-voltage side, medium-voltage side and high-voltage side for $100 \%$ of the rated power for each of them; $u_{i, j}^{\text {scm }}=\left\{\mathrm{U}_{i, j, n}^{\mathrm{scm}}\right\}$ is a subset of the values of the rated voltage on the low-voltage side, medium-voltage side and high-voltage side; $z_{i, j}^{\text {tr }}=\left\{\operatorname{Im}\left(Z_{i, j, n}^{\text {im }}\right), \operatorname{Re}\left(Z_{i, j, n}^{\text {im }}\right),\left|Z_{i, j, n}^{\text {scm }}\right|, \operatorname{Im} Z_{i, j, n}^{\text {scm }}, \operatorname{Re}\left(Z_{i, j, n}^{\text {scm }}\right),\left|Z_{i, j, n}^{\text {scm }}\right|\right\}$ is a subset of resistances of L-shaped substitution schemes for rated parameters; $f_{i, j}^{\mathrm{tr}}=\left\{F_{i, j, n}^{\mathrm{tr}}\left(\zeta_{i, j, n}^{\mathrm{im}}, \zeta_{i, j, n}^{\mathrm{im}}, \mathrm{K}_{i, j, n}^{\mathrm{scm}}, \mathrm{i}_{i, j, n}^{\mathrm{scm}}, \mathrm{u}_{i, j, n}^{\mathrm{tr}}, z_{i, j, n}^{\mathrm{tr}}\right)\right\}$ is a subset of functional relationship; $n=\left(1, N^{s t}\right), N^{s t}$ is a number of stages of the VRS and SDWF; $N^{t r}$ is a number of transformers in the production program; $N^{s}-$ is a number of series in the production program.

If defined a specializations' set (10) and a set of rated parameters of transformer products (11), that for idle modes $P_{i m}^{\text {ap }}$ :

$$
P_{i m, i, \alpha}^{\mathrm{ap}}=\max \left(P_{i m, i, \alpha}^{\mathrm{ap}}\right),\left.\quad q_{i}^{\mathrm{ap}}\right|_{P_{\mathrm{im}}, i_{\mathrm{im}}}=\left.\left\{q_{i, \alpha}^{\mathrm{ap}}\right\}\right|_{P_{\mathrm{im}}, i_{\mathrm{im}}}
$$

where $\left.q_{i}^{\text {ap }}\right|_{P_{\text {im }},,_{\text {im }}} \in\left\{q_{i, \alpha}^{\text {ap }}\right\}, i \in\left(1, N^{\text {ap }}\right), \forall \alpha \in\left\{M_{i}\right\}$.

For short circuit modes $P_{\text {im }}^{\text {ap }}$ :

$$
P_{\mathrm{scm}, i, \alpha}^{\mathrm{ap}}=\max \left(P_{\mathrm{scm}, i, \alpha}^{\mathrm{ap}}\right),\left.\quad q_{i}^{\mathrm{ap}}\right|_{P_{\mathrm{scm}}, \mathrm{u}_{\mathrm{scm}}}=\left.\left\{q_{i, \alpha}^{\mathrm{ap}}\right\}\right|_{P_{\mathrm{scm}}, \mathrm{u}_{\mathrm{scm}}},
$$

where $\left.q_{i}^{\mathrm{ap}}\right|_{P_{\mathrm{scm}}, \mathrm{u}_{\mathrm{scm}}} \in\left\{q_{i, \alpha}^{\mathrm{ap}}\right\}, i \in\left(1, N^{\mathrm{ap}}\right), \forall \alpha \in\left\{M_{i}\right\}$.

Thus it is possible to determine the set of parameters of the i-th active part of a transformer (8) in the form:

where $\forall \alpha \in\left\{M_{i}\right\}$.

$$
q_{i}^{\mathrm{ap}}=\left.q_{i}^{\mathrm{ap}}\right|_{P_{\mathrm{im}}, i_{\mathrm{im}}} \times\left. q_{i}^{\mathrm{ap}}\right|_{P_{\mathrm{scm}}, \mathrm{u}_{\mathrm{sem}}}=\left\{\left(\left.q_{i, \alpha}^{\mathrm{ap}}\right|_{P_{\mathrm{im}}, i_{\mathrm{im}}} ;\left.q_{i, \alpha}^{\mathrm{ap}}\right|_{P_{\mathrm{scm}}, \mathrm{u}_{\mathrm{scm}}}\right)\right\} \text {, }
$$


Thus, for the set of active parts of a transformer (14) the rated parameters of transformers of different types, geometric dimensions and mass are taken into account. Transformers with different designs of active parts, magnetic systems, windings and lead-out system can hold the same parameters. That is, different in design active parts can be the final elements of the same types of power transformers. But not every active part can ensure the fulfillment of all tasks from the set (5).

The achieved objective from the set (14), which corresponds to the rated data and characteristics of the power transformer, can be represented by a vector or a point in the state space: $c_{A, \alpha, i} \in c_{A, \alpha},\left(q_{i}^{\text {ap }} \in Q^{\text {ap }}\right), i \in N^{\text {ap }}, \alpha \in\left\{M_{i}\right\}$. Therefore, the possibilities of the $i$-th design of the active part $q_{i}^{\text {ap }} \in Q^{\text {ap }},\left(c_{A, \alpha, i} \in c_{A, \alpha}\right), i \in N^{\text {ap }}, \alpha \in\left\{M_{i}\right\}$ can provide the design parameters and characteristics of the power transformer are described in the state space by some hyperplane $L_{i}\left(c_{A, M}\right)$. Its boundaries are determined by the sets of input and output parameters and their numerical values for each power transformers.

It is necessary to consider, that the individual components of the active parts, for example, magnetic systems of the $i$-th type $q_{i}^{\mathrm{ms}} \in Q^{\mathrm{ms}}, i \in\left(1, N^{\mathrm{ms}}\right)$ , may be components for one or more series of power transformers. That is, to be part of different structures in accordance with an explicit objective, from the set (14).

Operation of a $i$-th active part of a power transformer in the structure of the power transformer is provided by measuring voltage transformer and measuring current transformer, devices for voltage regulation and with switching without excitation, protection systems, cooling systems of different types, external high-voltage lead-out systems and voltage control devices, between the inputs to the windings and external lead-out systems.

On the basis of relations and the generalized structures of active parts with magnetic systems, windings' system, and also lead-out systems for explicit series of power transformers, the generalized structures are formed:

$$
\begin{aligned}
& Q^{\text {ap }}=\left\{q_{i, \alpha}^{\text {ap }}\right\}, \\
& Q^{\text {los }}=\left\{q_{i, \alpha}^{\text {los }}\right\},
\end{aligned}
$$

where $\forall i \in\left(1, N^{\text {ap }}\right), \forall i \in\left(1, N^{\text {los }}\right), \forall \alpha \in\left\{M_{i}\right\}$. 
The sets (15), (16) owned to a series of transformers:

$$
q^{\text {tr }}=\left\{q_{i, j}^{\text {tr }}\right\}
$$

where $i \in\left(1, N^{s}\right), j \in\left(1, N^{\mathrm{tr}}\right)$.

And those sets, by-turn - the set of production program:

where $i \in\left(1, N^{s}\right)$.

$$
Q^{\text {tr }}=\left\{Q_{i}^{\text {tr }}\right\} \text {. }
$$

Relationships (1) - (18) allow to create the structure of the power transformer, which reflects the composition of its mold elements, parameters, characteristics and functional relationships. Its functional relationships can ensure the achievement of the objective for an explicit type of the ${ }^{\alpha}$-th product:

$$
q_{\Sigma \alpha}=\left\{q_{i, \alpha}^{\mathrm{ap}}, q_{j, \alpha}^{\mathrm{los}}\right\},
$$

where $i \in\left(1, N^{\text {ap }}\right), j \in\left(1, N^{\text {los }}\right), \alpha \in\left(1, \chi_{A}\right)$.

Thus, each objective in the task of designing a power transformer is defined by the local structure ${ }^{q} \sum_{\alpha}$. It allows to realize the process of converting electrical energy with some parameters to other parameters at a constant $\mathrm{AC}$ frequency. The complexity of the local structure of the power transformer is determined by the total number of acceptable types of design of the active parts. For them, the process of parameter transformation is provided by an explicit design of the active part of the set of final elements for a series of transformers (17). Therefore, the set of objective (1), (2) can be defined as a set of local structures of the form:

where $\forall \alpha \in\left\{1, \chi_{A}\right\}$.

$$
Q_{\Sigma}=\left\{q_{\sum \alpha}\right\},
$$

Synthesis of local structures (16) and macrostructure (17) of a power transformer is based on sets of the form (7), (14), (17), (19) for its active and final elements with sets of structures for VRS $Q^{\mathrm{VRS}}$ and SDWF $Q^{\mathrm{SDWF}}$ :

$$
\tilde{Q}=Q^{\mathrm{ap}} \cup Q^{\mathrm{los}} \cup Q^{\mathrm{VRS}} \cup Q^{\mathrm{SDWE}} \text {. }
$$

Thus, each local structure of the power transformer (20), which ensures the achievement of a specific objective from the set (1), (2) corresponds to a finite subset of interconnected and interacting elements from the set (21). 


\section{Creation a macrostructure of power transformers for projects of new types of power transformers}

Active elements in such local structures can be repeated. For example, main and longitudinal insulation elements, rods, barriers, bakelized-paper insulator, layers, spacer layers, winding wires, individual windings, parts and assemblies for tightening and pressing, low, medium or high voltage lead-out system, etc.

Thus, expression (21) describes the macrostructure of the power transformer as a set of local structures for the nomenclature set of objective (1), (2).

Therefore, the synthesis of a complex generalized structure of power transformers can be reflected taking into account the $\alpha$ - order union of the respective sets of active parts into sets $Q^{\text {ap }}$. For different order of tuples of local structures, their lengths are aligned by adding empty elements.

Therefore, the macrostructure (21) has a relation corresponding to each final objective from the set (1), (2) and, accordingly, to each of the set of the active part. The number of objectives of the macrostructure (21) includes a subset of the objectives of the production program, the advantage of the structure (21) is the reserve of safety. It eliminates re-synthesis, when changing this production program due to new tenders and contracts for the manufacturing and suppling of nomenclature transformer products. Therefore, for the macrostructure in the form of (21) its new synthesis should be excluded if it is necessary to add to the production program already mastered at the enterprise types of products. However, for new types of products it is necessary to synthesize new local structures:

where $\forall \alpha \in\left\{\chi_{A}, \chi_{E}\right\}$.

$$
Q_{\text {Erated }}=\bigcup_{\alpha} q_{\sum \alpha},
$$

By combining its tuple with the tuple (21), a new macrostructure is synthesized:

where $\forall \alpha \in\left\{1, \chi_{E}\right\}$.

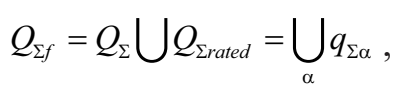

The set of local (internal) functional relationships of parameters for the active and final elements in the macrostructure of the complex (23) can be expressed by the ratio: 


$$
f_{1}^{\mathrm{s}}=\left\{f_{i, \alpha}^{\mathrm{ap}}\right\} \bigcup\left\{f_{m, n, \alpha}^{\mathrm{los}}\right\} \bigcup\left\{f_{k, j}^{\mathrm{VRS}}\right\} \bigcup\left\{f_{k}^{\mathrm{sDWF}}\right\},
$$

where $\alpha \in\left(1, \chi_{A}\right), i \in\left(1, N^{\text {ap }}\right), j \in\left(1, N^{\text {los }}\right), k \in\left(1, N^{\mathrm{VRS}}\right), m \in\left(1, N^{\mathrm{SDWF}}\right)$, $\eta \in\left(1, \mathrm{H}_{m}\right)$.

The number of such local functional relationships of parameters will be proportional to the product:

$$
N_{k}^{\mathrm{f}} \sim N^{\mathrm{ap}} \cdot N^{\mathrm{los}} \cdot N^{\mathrm{VRS}} \cdot N^{\mathrm{SDWF}} .
$$

The local functional set (24) should be supplemented by a set of global functional relationships, describing the interaction and interference of the active and final elements of the complex on each other:

$$
f_{\mathrm{g}}^{\mathrm{s}}=\left\{f_{(i, j)}^{\mathrm{s}}\right\}, i \neq j, i, j \in\left(1, N^{\mathrm{ap}}+N^{\mathrm{los}}+N^{\mathrm{VRS}}+N^{\mathrm{SDWF}}\right) .
$$

Thus, the functional set in the macrostructure of the complex of transformer products can be determined from relations (20), (21) in the form:

$$
f_{\Sigma}=f_{1}^{\mathrm{s}} \cup f_{\mathrm{g}}^{\mathrm{s}}=\left\{F_{\Sigma, \beta}^{\mathrm{ls}}\right\},
$$

where $\left\{F_{\Sigma, \beta}^{\text {ls }}\right\}$ is a set of internal and external functional relationships for the set of local structures $\{\beta\}$.

\section{Creation a substructure of computational techniques for the design of power transformers}

All input and output parameters for the design of power transformers can be divided into three groups.

The first discrete-material group includes the parameters of the active parts of different types of power transformers, corresponding to the set of product nomenclature, as well as the parameters of a subset of winding materials, electrical steel packages and electrical insulating layers, branch packages and lead-out system:

$$
\left\{\begin{array}{l}
X_{\beta}^{\mathrm{dm}}=\left\{x_{i, \beta}^{\mathrm{dm}}\right\}, i=\overline{1, n_{\mathrm{dm}}}, \\
Y_{\beta}^{\mathrm{dm}}=\left\{y_{j, \beta}^{\mathrm{dm}}\right\}, j=\overline{1, m_{\mathrm{dm}}} .
\end{array}\right.
$$

The second continuously-material group includes a sets of electrical and magnetic parameters of power transformers, including systems of its final elements: 


$$
\left\{\begin{array}{l}
X_{\beta}^{\mathrm{cm}}=\left\{x_{i, \beta}^{\mathrm{cm}}\right\}, i=\overline{1, n_{\mathrm{cm}}}, \\
Y_{\beta}^{\mathrm{cm}}=\left\{y_{j, \beta}^{\mathrm{cm}}\right\}, j=\overline{1, m_{, \mathrm{m}}} .
\end{array}\right.
$$

To the third group - a sets of a parameters of interface (information) channels:

$$
\left\{\begin{array}{l}
X_{\beta}^{\mathrm{i}}=\left\{x_{i, \beta}^{\mathrm{i}}\right\}, i=\overline{1, n_{\mathrm{i}}}, \\
Y_{\beta}^{\mathrm{i}}=\left\{y_{j, \beta}^{\mathrm{i}}\right\}, j=\overline{1, m_{\mathrm{i}}} .
\end{array}\right.
$$

The corresponding sets of input and output parameters can be defined from (28) - (30) in the form:

$$
\left\{\begin{array}{l}
X_{\beta}^{\mathrm{ls}}=X_{\beta}^{\mathrm{cm}} \cup X_{\beta}^{\mathrm{cm}} \cup X_{\beta}^{\mathrm{i}}, n_{\beta}=n_{\mathrm{dm}}+n_{\mathrm{cm}}+n_{\mathrm{i}}, \\
Y_{\beta}^{\mathrm{ls}}=Y_{\beta}^{\mathrm{cm}} \cup Y_{\beta}^{\mathrm{cm}} \cup Y_{\beta}^{\mathrm{i}}, m_{\beta}=m_{\mathrm{dm}}+m_{\mathrm{cm}}+m_{\mathrm{i}} .
\end{array}\right.
$$

Taking into account (28) the function for the $\beta$-th local structure of the complex:

$$
F_{\beta}:\left\{X_{\beta}^{\mathrm{dm}} \cup X_{\beta}^{\mathrm{cm}} \cup X_{\beta}^{\mathrm{i}}\right\} \rightarrow\left\{Y_{\beta}^{\mathrm{dm}} \cup Y_{\beta}^{\mathrm{cm}} \cup Y_{\beta}^{\mathrm{i}}\right\} .
$$

The process of transforming the parameters of electrical energy is not shape-generating, then changes in the dimensions and relative position of the windings, elements of electrical insulation, during operation, can be neglected.

The set of parameters of a discrete-material group (2.28) in the local structures of the complex (2.21) has the properties of invariance, relating to the sets of parameters of the continuously-material group (2.31) and interface channels group (2.32). That is, the relations are fair:

$$
\left\{\begin{array}{l}
\left.X_{\beta}^{\mathrm{dm}}\right|_{\text {los,VRS,SDWF }}=\left.Y_{\beta}^{\mathrm{dm}}\right|_{\text {los,VRS,SDWF }}, \\
\left.\left\{x_{i, \beta}^{\mathrm{dm}}\right\}\right|_{\text {los,VRS,SDWF }}=\left.\left\{y_{i, \beta}^{\mathrm{dm}}\right\}\right|_{\text {los,VRS,SDWF }}, i=\overline{1, n_{\mathrm{dm}}} .
\end{array}\right.
$$

Therefore, the parameters of this group are invariance to the sets of parameters (31), (32). Thus, subsets of parameters by expression (31) $[11$, p. 94], according to, then for the set:

$$
\{p\}=\{X\} \bigcup\{Y\},
$$

where 


$$
\left\{\begin{array}{l}
X=\left\{X_{\beta}^{l s}\right\}, \\
Y=\left\{Y_{\beta}^{l s}\right\},
\end{array}, \forall \beta \in\{\beta\},\right.
$$

a subsets of invariance $\{\operatorname{Inv}\}$, independently variable $\left\{N_{\mathrm{var}}\right\}$ and dependent parameters are exuded [12, p. 89]:

$$
\{p\}=\{\operatorname{Inv}\} \bigcup\left\{N_{\text {var }}\right\} \bigcup\left\{N_{\text {fun }}\right\}
$$

The number of dependent parameters $\left\{N_{\text {var }}\right\}$ should correspond to the total number of ratios of the calculation method for (32). A dimension of the vector $\left\{N_{\text {var }}\right\}$ is much smaller than the dimension of the vector $\{p\}$, then a numerical implementation of design objective is significantly simplified.

\section{Creation a structure of parameters and equivalent circuit of power transformers}

A character of the considered local structures of power transformers according to (20) is a significant excess of active power losses and reactive power in the short-circuit mode over the parameters of the idle mode. Further reduction of a set's order of independent parameters of the $\varphi$-th product can be realized by decomposing the structure (18) into substructures.

The magnetic field in the substructures or in the active elements of the local structure of the complex according to (18) is created by currents in a system of electrical circuits $j \in\left(1, n_{\mathrm{AC}, i}\right)$ and included in the set of the form:

$$
\left\{\dot{I}_{\Sigma, i}=\left\{\left.I_{i, j} \cdot e^{-j \phi_{i, j}}\right|_{\tau=\tau_{l}}\right\}\right.
$$

where $j \in\left(1, n_{\mathrm{AC}, i}\right), \forall i \in\left(1, N_{i}\right) ; n_{\mathrm{AC}, i}$ is a number of circuits with currents of the $i$-th active element or $i$-th substructure of the local structure, according to (18).

A magnetic field self-energy of circuits with currents (36) can be represented by the relations according to [13, p. 20]:

$$
W_{\mathrm{self}, i}=\frac{1}{2} \sum_{j=1}^{n_{\mathrm{AC}, i}} L_{j} \cdot I_{i, j}^{2},
$$

where $\forall l \in\left(1, N_{l}\right), \forall i \in\left(1, N_{i}\right)$. 
Their mutual magnetic energy can be represented as [3]:

$$
W_{\text {mutual }, i}=\frac{1}{2} \sum_{k=1}^{n_{\mathrm{AC}, i}} \sum_{j=1, k \neq j}^{n_{\mathrm{AC}, i}} M_{i, k, j} \cdot I_{i, k} \cdot I_{i, j}
$$

where $\forall l \in\left(1, N_{l}\right), \forall i \in\left(1, N_{i}\right)$.

Then the magnetic field energy in the substructures or active elements of the local structure of the active part (18) will be determined by the algebraic sum of expressions (37) and (38):

$$
W_{\mathrm{m}, i}=W_{\mathrm{self}, i}+W_{\text {mutual }, i}=\frac{1}{2}\left(\sum_{j=1}^{n_{\mathrm{AC}, i}} L_{j} \cdot I_{i, j}^{2} \pm \frac{1}{2} \sum_{k=1}^{n_{\mathrm{AC}, i}} \sum_{j=1, k \neq j}^{n_{\mathrm{AC}, i}} M_{i, k, j} \cdot I_{i, k} \cdot I_{i, j}\right)
$$

where $\forall l \in\left(1, N_{l}\right), \forall i \in\left(1, N_{i}\right)$.

Reactive power:

$$
Q_{i}=\omega \cdot W_{\mathrm{m}, i}=\left.2 \pi \cdot f \cdot W_{\mathrm{m}, i}\right|_{\tau=\tau_{l}},
$$

where $\forall l \in\left(1, N_{l}\right), \forall i \in\left(1, N_{i}\right)$.

In this case, the inductances and mutual inductances in the relations (36) - (38) has an energy definition. That is, determine the measure of the self and mutual magnetic field energy of the circuits with a current, where the active value is equal to $1 \mathrm{~A}$ for the substructures of active elements or active elements in the local structure (18).

Active power losses can be defined as:

$$
P_{i}=\left.\sum_{j=1}^{n_{\mathrm{AC}, i}} R_{\mathrm{DC}, j} \cdot k_{\mathrm{add}, j} \cdot I_{i, j}^{2}\right|_{\tau=\tau_{l}},
$$

where $\forall l \in\left(1, N_{l}\right), \forall i \in\left(1, N_{i}\right) ; R_{\mathrm{DC}}-\mathrm{DC}$ resistance, $\Omega ; k_{\text {add }}$-additional losses coefficient.

Apparent power is calculated as the geometric sum of the components of its active losses (41) and reactive power (40):

where $\forall l \in\left(1, N_{l}\right), \forall i \in\left(1, N_{i}\right)$.

$$
S_{i}=\left.\sqrt{P_{i}^{2}+Q_{i}^{2}}\right|_{\tau=\tau_{l}}
$$

Known methods for determining the inductance and mutual inductance of the windings system circuits of the active part, lead-out system and other conductive elements can be implemented only if the phases of local current 
density vectors in the volume of conductive media are distributed evenly $[14$, p. 30$]$. However, the actual phase changes in this distribution can be quite significant [15, p. 72]. This limits the application of the above methods by calculating the initial approximation of the magnetic field energy $W_{\mathrm{m}, i}$ , reactive power $Q_{i}$, active power $P_{i}$ and apparent power $S_{i}$. Therefore, at their calculations it is necessary to apply integral relations $[16, \mathrm{p} .6]$ :

$$
\begin{gathered}
P_{i}=\sum_{j=1}^{n_{\mathrm{AC}, i}} \iiint_{V_{i, j}} \sigma_{i, j}(\theta)^{-1}\left|\dot{\mathbf{J}}_{i, j}\right|^{2} d x d y d z, \\
Q_{i}=\frac{\omega}{2} \sum_{j=1}^{n_{\mathrm{AC}, i}} \iiint_{V_{i, j}} \mu_{i, j} \mu_{0}\left(\dot{\mathbf{H}}_{i, j}(x, y, z), \dot{\mathbf{H}}_{i, j}(x, y, z)\right) d x d y d z,
\end{gathered}
$$

where $\forall l \in\left(1, N_{l}\right), \forall i \in\left(1, N_{i}\right) ; \sigma(\theta)$ is an electrical conductivity; $(\theta)$ is a local temperature; $\mathbf{J}=\mathbf{J}(x, y, z)$ is a vector of current density amplitudes; $\dot{\mathbf{H}}=\dot{\mathbf{H}}(x, y, z)$ is a vector of amplitudes of magnetic field; $\mu, \mu_{0}$ is a relative magnetic permeability and magnetic permeability of vacuum.

In addition, the relations (43) - (44) allow to determine the volumes of the subareas of electromagnetic and electro-thermal conversion of AC energy for substructures, as the sum of the volumes for the components of their active elements [17, p 211]:

$$
\iiint_{V} d x d y d z=\sum_{i} \iint_{V_{i}} d x d y d z
$$

A resistances of substructures of the power transformer or its operating elements can be presented in the form [18, p. 89]:

$$
\begin{gathered}
Z_{i}=\left.\left|Z_{i}\right| e^{j \phi_{i}}\right|_{\tau=\tau_{l}}, \\
\left|Z_{i}\right|=S_{i} /\left.\left|\dot{\mathbf{I}}_{i}\right|^{2}\right|_{\tau=\tau_{l}}, \\
\dot{\mathbf{I}}_{i}=\left.\sum_{j=1}^{n_{\mathrm{AC}, i}} \dot{\mathbf{I}}_{i, j}\right|_{\tau=\tau_{l}}, \\
\phi_{i}=\left.\arccos \left(P_{i} / S_{i}\right)\right|_{\tau=\tau_{l}},
\end{gathered}
$$

where $\forall i \in\left(1, N_{i}\right) ;\left|Z_{i}\right|, \phi_{i}$ is a modulus and phase of impedance of the $i$-th active element; $\dot{\mathbf{I}}_{i}$ is a current amplitude of the $i$-th active element; 
$\dot{\mathbf{I}}_{i, j}=\mathbf{i} \dot{\mathbf{I}}_{x, i, j}+\mathbf{j} \dot{\mathbf{I}}_{y, i, j}+\mathbf{k} \dot{\mathbf{I}}_{z, i, j}$ is a current of the $j$-th branch of the $i$-th active element; $(\mathbf{i}, \mathbf{j}, \mathbf{k})$-is a unit vectors of the of the Cartesian coordinate system.

A currents, which flowing through an explicit area $S\left(S_{y z}, S_{x z}, S_{x y}\right)_{j}$ are determined by simulation data:

$$
\left\{\begin{array}{l}
\dot{\mathbf{I}}_{i, j}=\sqrt{\left|\dot{\mathbf{I}}_{x, i, j}\right|^{2}+\left|\dot{\mathbf{I}}_{y, i, j}\right|^{2}+\left|\dot{\mathbf{I}}_{z, i, j}\right|^{2}}, \forall l \in\left(1, N_{l}\right), \forall i \in\left(1, N_{i}\right) \\
\dot{\mathbf{I}}_{x, i, j}=\iint_{S_{y z}} \mathbf{J}_{x}(x, y, z) d y d z, \\
\dot{\mathbf{I}}_{y, i, j}=\iint_{S_{y z}} \mathbf{j}_{y}(x, y, z) d y d z, \dot{\mathbf{I}}_{z, i, j}=\iint_{S_{y z}} \mathbf{J}_{z}(x, y, z) d y d z .
\end{array}\right.
$$

Resistances by expressions (46) - (49) can be expressed through their active and reactive components:

$$
\begin{gathered}
R_{i}=\left|Z_{i}\right| \cdot \cos \left(\phi_{i}\right), \\
X_{i}=\left|Z_{i}\right| \cdot \sin \left(\phi_{i}\right), \\
Z_{i}=R_{i}+j X_{i} .
\end{gathered}
$$

The need for consideration of the nonlinear properties of the media, the uneven distribution of currents in the integral expressions (43), (44), (50) for calculating a resistance (46) - (49), (51) - (53) justify the implementation of a $3 \mathrm{D}$ modeling of electromagnetic and electro-thermal processes in current and final elements of the transformer complex. The space 3D modeling can ensure the high accuracy of the identification of the parameters and the characteristics of the active elements of the transformer structure by (17), their interaction between different active elements of the transformer substructures.

\section{Conclusions}

The mathematical description of power transformers projects was offered, as a set of geometrical forms, geometrical dimensions of details, knots, systems and etc. The mathematical description of power transformers projects is supplemented by mathematical descriptions of physical properties, rated parameters and parameters of circuit models of electromagnetic conversion of $\mathrm{AC}$ electric energy in testing and rated modes of operation. 
To generalize the project structure of different types of power transformers, it is proposed to compensate the dimensionality of the corresponding tuples of parameters of active elements, mathematical descriptions of physical properties of active, insulating and structural materials by adding the tuple of a "zero" elements to their dimensionality. It dimensionality corresponds to the maximum dimensionality of tuples of transformer projects in the production program of the enterprise.

When combining tuples for projects of certain types of power transformers in the production program of the enterprise was proposed to create a unitary structure for existing projects of power transformers in the production program of the enterprise.

In the case of designing a new type of transformer, the creation of the updated unitary structure of power transformer projects was carried out by supplementing the existing unitary structure with a new tuple of design data.

Creation of a unitary structure of power transformer projects for the production program of the enterprise provides a significant time reduction to develop projects of new types of power transformers by importing the generated design data of the same parts, components, systems from previously developed power transformer projects.

Application of unitary structure of power transformers projects allows to reduce time for creation and import of detailed 3D geometric model of power transformer in structure of specialized software of field modeling of electromagnetic and electro-thermal processes. This allows to significantly reduce the cost of design preparation of production, increase the accuracy of design data and implement design solutions to increase the level of reliability and efficiency of operation of power transformers.

At the stage of development of tender proposals, the application of a unitary structure of projects can significantly reduce costs and time to determine the technical parameters and price proposals for new types of power transformers.

\section{References:}

1. Kulkarni S.V., Khaparde S.A. (2004). Transformer Engineering: Design and Practice. New York: Marcel Dekker.

2. Petrov G.N. (1974). Elektricheskiye mashiny [Electric machines]. Moscow: Energiya. (in Russian) 
3. Biki M.A. (2013). Proyektirovaniye silovykh transformatorov. Raschet osnovnykh parametrov [Designing power transformers. Calculation of basic parameters]. Moscow: Znak. (in Russian)

4. Colonel Wm., McLyman T. (2004). Transformer and Inductor Design Handbook. Third Edition (Electrical \& Computer Engineering). New York: Marcel Dekker.

5. Popov G.V., Tikhonov A.I., Klimov D.A. (2004). Komp'yuternaya sistema imitatsii dinamicheskikh protsessov v silovykh transformatorakh [Computer system for simulating dynamic processes in power transformers]. Electro: Electrical engineering, power engineering, electrical industry, no. 2, pp. 22-25.

6. Tikhonov A.I. (2005). Integrirovannaya issledovatel'skaya sreda matematicheskogo modelirovaniya elektromekhanicheskikh ustroystv [Integrated research environment for mathematical modeling of electromechanical devices]. Bulletin of the Scientific and Industrial Society, no. 9, pp. 55-59.

7. Tikhonov A.I., Kucherov S.Yu., Lashmanov I.M., Rubtsov D.V. (2006). Tekhnologiya chislennogo issledovaniya elektricheskikh mashin s ispol'zovaniyem biblioteki konechno-elementnogo modelirovaniya magnitnogo polya [Technology of numerical research of electrical machines using the library of finite element modeling of magnetic field]. Bulletin of ISUE, no. 3, pp. 5-8.

8. Yarymbash D., Yarymbash S., Divchuk T., Kotsur M., Kylymnyk I., Kulanina Y. (2019). Calculation of No-load Currents Using Hysteresis Loop. Proceedings of the International Conference on Modern Electrical and Energy Systems (Ukraine, Kremenchuk, 23-25 Sept. 2019), IEEEXplore, pp. 122-125. DOI: 10.1109/MEES.2019.8896366

9. Yarymbash D., Kotsur M., Kulanina Y., Divchuk T. (2019). Idling Mode Simulation of Single-Phase Transformer. Proceedings of the International Conference on Modern Electrical and Energy Systems (Ukraine, Kremenchuk, 23-25 Sept. 2019), IEEEXplore, pp. 118-121. DOI: 10.1109/MEES.2019.8896637

10. Yarymbash D.S. (2014). Osobennosti optimizatsii grafitatsii elektricheskikh rezhimov [Features of electric modes graphitization optimization]. Electrotechnical and computer systems, no. 15(91), pp. 215-219.

11. Yarymbash D.S., Yarymbash S.T. (2012). Povysheniye energoeffektivnosti kompleksa elektrografitizatsii pri modernizatsii bokovykh shinoprovodov moshchnykh pechey grafitatsii [Increasing the energy efficiency of the electrical graphitization complex during the modernization of side busbar packages of powerful graphitization furnaces]. Bulletin of SevNTU, no. 132, pp. 93-100.

12.Detlaf A.A., Yavorsky B.M., Milkovskaya L.B. (1977). Kurs fiziki. Elektrichestvo i magnetizm [Physics course. Electricity and magnetism]. Moscow: Vysshaya shkola. (in Russian)

13. Bida V.V., Vasetsky Yu.M., Zakharchenko S.V. (1990). K raschetu tokovedushchikh sistem, obrazovannykh konturami slozhnoy geometrii [To the calculation of current-carrying systems formed by contours of complex geometry]. Proceedings of the universities. Electromechanics, no. 6, pp. 19-21.

14. Vasetsky Yu.M., Kovbasenko Yu.P. (1987). K raschetu magnitnogo polya prostranstvennykh konturov s tokom [To the calculation of the magnetic field of 
spatial contours with current]. Proceedings of the universities. Electromechanics, no. 5, pp. 28-32.

15. Vasetsky Yu.M. (1989). Poverkhnostnyy effekt v massivnom provodnike, obrazuyushchem ploskiy kontur [Surface effect in a massive conductor forming a flat contour]. Technical electrodynamics, no. 12, pp. 72-74.

16. Vasetsky Yu.M. (1987). Priblizhennyy metod rascheta polya vnutri i vblizi ploskogo konturnogo provodnika [An approximate method for calculating the field inside and in the vicinity of a flat contour conductor]. Technical electrodynamics, no. 4 , pp. 5-7.

17. Kalantarov P.L., Zeitlin L.A. (1986). Raschet induktivnosti [Calculation of inductances]. Leningrad: Energoatomizdat. (in Russian)

18.Zeitlin L.A. (1950). Induktivnost' provodov i tsepey [Inductance of wires and circuits]. Moscow: Gosenergoizdat. (in Russian) 